\title{
Incidence of Surgical Site Infection After Spine Surgery: What Is the Impact of the Definition of Infection?
}

\author{
Sjoerd P. F. T. Nota MD, Yvonne Braun MD, \\ David Ring MD, PhD, Joseph H. Schwab MD, MS
}

Published online: 12 September 2014

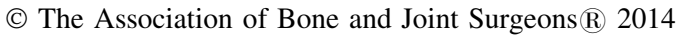

\begin{abstract}
Background Orthopaedic surgical site infections (SSIs) can delay recovery, add impairments, and decrease quality of life, particularly in patients undergoing spine surgery, in whom SSIs may also be more common. Efforts to prevent and treat SSIs of the spine rely on the identification and registration of these adverse events in large databases. The effective use of these databases to answer clinical questions depends on how the conditions in question, such as infection, are defined in the databases queried, but the degree to which different definitions of infection might cause
\end{abstract}

Each author certifies that he or she, or a member of his or her immediate family, has no funding or commercial associations (eg, consultancies, stock ownership, equity interest, patent/licensing arrangements, etc) that might pose a conflict of interest in connection with the submitted article.

All ICMJE Conflict of Interest Forms for authors and Clinical Orthopaedics and Related Research ${ }^{\circledR}$ editors and board members are on file with the publication and can be viewed on request.

Each author certifies that his or her institution approved the human protocol for this investigation, that all investigations were conducted in conformity with ethical principles of research.

Electronic supplementary material The online version of this article (doi:10.1007/s11999-014-3933-y) contains supplementary material, which is available to authorized users.

S. P. F. T. Nota, J. H. Schwab

Orthopaedic Spine Service \& Orthopaedic Oncology Service, Massachusetts General Hospital, Harvard Medical School, Boston, MA, USA

\section{S. P. F. T. Nota, Y. Braun, D. Ring ( $\square)$}

Orthopaedic Hand and Upper Extremity Service, Massachusetts

General Hospital, Harvard Medical School, Yawkey Center,

Suite 2100, 55 Fruit Street, Boston, MA 02114, USA

e-mail: dring@mgh.harvard.edu; dring@partners.org different risk factors to be identified by those databases has not been evaluated.

Questions/purposes The purpose of this study was to determine whether different definitions of SSI identify different risk factors for SSI. Specifically, we compared the International Classification of Diseases, 9th Revision (ICD9) coding, Centers for Disease Control and Prevention (CDC) criteria for deep infection, and incision and débridement for infection to determine if each is associated with distinct risk factors for SSI.

Methods In this single-center retrospective study, a sample of 5761 adult patients who had an orthopaedic spine surgery between January 2003 and August 2013 were identified from our institutional database. The mean age of the patients was 56 years $( \pm 16 \mathrm{SD})$, and slightly more than half were men. We applied three different definitions of infection: ICD-9 code for SSI, the CDC criteria for deep infection, and incision and débridement for infection. Three hundred sixty-one (6\%) of the 5761 surgeries received an ICD-9 code for SSI within 90 days of surgery. After review of the medical records of these 361 patients, 216 (4\%) met the CDC criteria for deep SSI, and 189 (3\%) were taken to the operating room for irrigation and débridement within 180 days of the day of surgery.

Results We found the Charlson Comorbidity Index, the duration of the operation, obesity, and posterior surgical approach were independently associated with a higher risk of infection for each of the three definitions of SSI. The influence of malnutrition, smoking, specific procedures, and specific surgeons varied by definition of infection. These elements accounted for approximately $6 \%$ of the variability in the risk of developing an infection.

Conclusions The frequency of SSI after spine surgery varied according to the definition of an infection, but the most important risk factors did not. We conclude that large 
database studies may be better suited for identifying risk factors than for determining absolute numbers of infections. Level of Evidence Level III, prognostic study. See Guidelines for Authors for a complete description of levels of evidence.

\section{Introduction}

Patients with orthopaedic surgical site infections (SSIs) have substantially greater physical limitations and a distinct decrease in quality of life [1]. In orthopaedic surgery, spine surgery has a relatively high incidence of SSIs [13]. The risk of SSI after spine surgery increases with the complexity of the patients and the procedure [10,12]. Prior research has identified several factors associated with an increased risk of SSI after spine surgery: increased age [5], obesity [3, 7], diabetes mellitus [11, 14], smoking [16], malnutrition [8], corticosteroid use [15] and prolonged duration of surgery [10], although these are somewhat inconsistent from study to study.

Efforts to prevent and treat SSIs of the spine rely on the identification and registration of these adverse events in large databases. The use of large databases relies on the methods by which coding data are translated into diagnoses. For instance, an SSI can be defined based on billing codes (International Classification of Diseases, 9th Revision system [ICD-9]), the Centers for Disease Control and Prevention (CDC) criteria for SSI, CDC criteria for deep SSI, and billing codes for irrigation and débridement (I\&D) of infection (Current Procedural Terminology). Do these different definitions lead to different numbers of infections? Perhaps even more importantly, does statistical analysis identify different factors associated with different definitions of SSIs after spine surgery?

We therefore sought to determine whether different definitions of SSI would identify different risk factors for SSI. Specifically, we compared the ICD-9 coding, CDC criteria for deep infection, and I\&D for infection to see whether each would be associated with different risk factors for SSI.

\section{Material and Methods}

\section{Study Design}

In this institutional review board-approved retrospective study, a sample of 9155 patients who had orthopaedic spine surgery between January 2003 and August 2013 were identified using Current Procedural Terminology (CPT) procedure codes (Appendix 1 [Supplemental materials are available with the online version of $\left.\left.\operatorname{CORR}^{\circledR}{ }^{\circledR}\right]\right)$. We excluded 229 procedures with a code for infection or abscess on the day of operation (ie, the indication for surgery was infection). We excluded 453 procedures in patients who were younger than 18 resulting in a provisional cohort of 8473 procedures.

For patients who had more than one spinal procedure, we tracked the first spine operation as the index procedure. This resulted in a final cohort of 5761 spinal procedures in 5761 patients. The mean age of the patients was $56 \pm 16$ (SD) years (range, 18-97 years and 1811 [31\%] of the 5761 patients who were older than 65 years old), and slightly more than half were men (Table 1). The mean followup for the cohort was 3 years (median 2 years), where $87 \%$ of the cohort was followed for more than 90 days and $80 \%$ of the patients were followed for more than 180 days.

Three hundred sixty-one $(6 \%)$ of the 5761 surgeries received an ICD-9 code (998.5, 998.51, 998.59, 996.60, 996.66, 996.67) for SSI within 90 days of surgery in our institutional database. After reviewing the medical records of these 361 patients, 216 (3.8\%) met the CDC criteria for deep SSI and 189 (3.2\%) were taken to the operating room for I\&D within 180 days of the day of surgery. The CDC criteria for deep infection are purulent drainage from the deep incision or a deep incision that spontaneously dehisces or is deliberately opened by a surgeon and is either culture-positive or not cultured but the patient has a fever $\left(>38^{\circ} \mathrm{C}\right)$ and/or localized pain or tenderness. One hundred eighty days was chosen for I\&D based on our clinical experience of the development of SSIs and these wounds were considered infected if the wound cultures were positive and/or the attending surgeon deemed the wound to be grossly infected on direct inspection during surgery. Depending on the endpoint, respectively, $361(6 \%)$ (Table 1), 216 (4\%) (Table 2), and 189 (3\%) (Table 3) of the patients developed a SSI after surgery.

\section{Patient-related Factors}

In addition to demographics, we accounted for a patient's combined comorbidities (including diabetes mellitus) at the moment of orthopaedic spine surgery by calculating the Charlson Comorbidity Index (CCI) [4] based on our own developed ICD-9 code-driven algorithm. We also studied the effect of corticosteroid use, obesity, malnutrition, and smoking based on ICD-9 codes.

\section{Technical Factors}

The type of spine surgery performed was categorized as follows: anterior versus posterior approach; cervical versus 
Table 1. Bivariate analyses: ICD-9 code for infection $(n=5761)$

\begin{tabular}{|c|c|c|c|c|c|c|}
\hline \multirow[t]{2}{*}{ Parameter } & \multicolumn{2}{|c|}{ No $(\mathrm{n}=5400[94 \%])$} & & \multicolumn{3}{|c|}{ Yes $(\mathrm{n}=361[6.3 \%])$} \\
\hline & Mean (SD) & Range & & Mean (SD) & Range & $\mathrm{p}$ value \\
\hline Age (years) & $55(16)$ & $18-97$ & & $56(17)$ & $19-96$ & 0.48 \\
\hline Charlson index & $1.7(2.5)$ & $0-14$ & & $2.9(3.1)$ & $0-15$ & $<0.001$ \\
\hline \multirow[t]{2}{*}{ Duration (hours), $\mathrm{n}=5214$} & $3.5(2.1)$ & $0.22-18$ & & $4.3(2.6)$ & $0.65-15$ & $<0.001$ \\
\hline & & Number & Percent & Number & Percent & \\
\hline \multicolumn{7}{|l|}{ Sex } \\
\hline Male & & 2844 & 53 & 197 & 55 & 0.48 \\
\hline Female & & 2556 & 47 & 164 & 45 & \\
\hline \multicolumn{7}{|l|}{ Smoking } \\
\hline Yes & & 430 & 8.0 & 43 & 12 & 0.008 \\
\hline No & & 4970 & 92 & 318 & 88 & \\
\hline \multicolumn{7}{|l|}{ Malnutrition } \\
\hline Yes & & 332 & 6.1 & 35 & 10 & 0.008 \\
\hline No & & 5068 & 94 & 326 & 90 & \\
\hline \multicolumn{7}{|l|}{ Obesity } \\
\hline Yes & & 81 & 1.5 & 19 & 5.3 & $<0.001$ \\
\hline No & & 5319 & 99 & 342 & 95 & \\
\hline \multicolumn{7}{|l|}{ Steroid use } \\
\hline Yes & & 19 & 0.35 & 4 & 1.1 & 0.052 \\
\hline No & & 5381 & 100 & 357 & 99 & \\
\hline \multicolumn{7}{|l|}{ Morselized graft use } \\
\hline Yes & & 1809 & 34 & 147 & 41 & 0.005 \\
\hline No & & 3591 & 67 & 214 & 59 & \\
\hline \multicolumn{7}{|l|}{ Structural graft use } \\
\hline Yes & & 836 & 15 & 45 & 12 & 0.12 \\
\hline No & & 4564 & 85 & 316 & 88 & \\
\hline \multicolumn{7}{|l|}{ Vancomycin prophylaxis } \\
\hline Yes & & 81 & 1.5 & 3 & 0.83 & 0.49 \\
\hline No & & 5319 & 99 & 358 & 99 & \\
\hline \multicolumn{7}{|l|}{ Type of procedure } \\
\hline Anterior & & 1348 & 25 & 65 & 18 & 0.003 \\
\hline Posterior & & 2004 & 37 & 183 & 51 & $<0.001$ \\
\hline Cervical & & 1446 & 27 & 85 & 24 & 0.18 \\
\hline Thoracic & & 575 & 11 & 68 & 19 & $<0.001$ \\
\hline Lumbar & & 3699 & 69 & 234 & 65 & 0.15 \\
\hline Sacral & & 49 & 0.91 & 11 & 3.0 & $<0.001$ \\
\hline Single level & & 4437 & 82 & 301 & 83 & 0.56 \\
\hline Laminectomy/discectomy/p & ion vertebra & 4894 & 91 & 316 & 88 & 0.053 \\
\hline Fusion/arthrodesis & & 2580 & 48 & 190 & 53 & 0.074 \\
\hline Osteotomy & & 124 & 2.3 & 19 & 5.3 & $<0.001$ \\
\hline Instrumentation & & 2894 & 54 & 209 & 58 & 0.11 \\
\hline Trauma & & 250 & 4.6 & 21 & 5.8 & 0.30 \\
\hline Oncology & & 287 & 5.3 & 43 & 12 & $<0.001$ \\
\hline Oncology—benign & & 83 & 1.5 & 10 & 2.8 & 0.072 \\
\hline Other & & 2487 & 46 & 186 & 52 & 0.044 \\
\hline
\end{tabular}

ICD-9 = International Classification of Diseases, 9th Revision. 
Table 2. Bivariate analyses: CDC criteria for deep infection $(\mathrm{n}=5761)$

\begin{tabular}{|c|c|c|c|c|c|c|}
\hline \multirow[t]{2}{*}{ Parameter } & \multicolumn{2}{|c|}{ No $(\mathrm{n}=5545[96 \%])$} & & \multicolumn{3}{|c|}{ Yes $(n=216[3.7 \%])$} \\
\hline & Mean (SD) & Range & & Mean (SD) & Range & $\mathrm{p}$ value \\
\hline Age (years) & $55(16)$ & $18-97$ & & $57(17)$ & $20-96$ & 0.10 \\
\hline Charlson index & $1.8(2.5)$ & $0-15$ & & $2.9(3.1)$ & $0-11$ & $<0.001$ \\
\hline \multirow[t]{2}{*}{ Duration (hours), $\mathrm{n}=5214$} & $3.5(2.1)$ & $0.22-18$ & & $4.4(2.7)$ & $0.75-15$ & $<0.001$ \\
\hline & & Number & Percent & Number & Percent & \\
\hline \multicolumn{7}{|l|}{ Sex } \\
\hline Male & & 2920 & 53 & 121 & 56 & 0.33 \\
\hline Female & & 2625 & 47 & 95 & 44 & \\
\hline \multicolumn{7}{|l|}{ Smoking } \\
\hline Yes & & 443 & 8.0 & 30 & 14 & 0.002 \\
\hline No & & 5102 & 92 & 186 & 86 & \\
\hline \multicolumn{7}{|l|}{ Malnutrition } \\
\hline Yes & & 342 & 6.2 & 25 & 12 & 0.001 \\
\hline No & & 5203 & 94 & 191 & 88 & \\
\hline \multicolumn{7}{|l|}{ Obesity } \\
\hline Yes & & 90 & 1.6 & 10 & 4.6 & 0.001 \\
\hline No & & 5455 & 98 & 206 & 95 & \\
\hline \multicolumn{7}{|l|}{ Steroid use } \\
\hline Yes & & 20 & 0.36 & 213 & 99 & 0.053 \\
\hline No & & 5525 & 100 & 3 & 1.4 & \\
\hline \multicolumn{7}{|l|}{ Morselized graft use } \\
\hline Yes & & 1863 & 34 & 93 & 43 & 0.004 \\
\hline No & & 3682 & 66 & 123 & 57 & \\
\hline \multicolumn{7}{|l|}{ Structural graft use } \\
\hline Yes & & 860 & 16 & 21 & 10 & 0.020 \\
\hline No & & 4685 & 84 & 195 & 90 & \\
\hline \multicolumn{7}{|l|}{ Vancomycin prophylaxis } \\
\hline Yes & & 84 & 1.5 & 0 & 0 & 0.077 \\
\hline No & & 5461 & 98 & 216 & 100 & \\
\hline \multicolumn{7}{|l|}{ Type of procedure } \\
\hline Anterior & & 1380 & 25 & 33 & 15 & 0.001 \\
\hline Posterior & & 2070 & 37 & 117 & 54 & $<0.001$ \\
\hline Cervical & & 1486 & 27 & 45 & 21 & 0.052 \\
\hline Thoracic & & 605 & 11 & 38 & 18 & 0.002 \\
\hline Lumbar & & 3786 & 68 & 147 & 68 & 0.95 \\
\hline Sacral & & 51 & 0.92 & 9 & 4.2 & $<0.001$ \\
\hline Single level & & 4551 & 82 & 187 & 87 & 0.090 \\
\hline Laminectomy/discectomy/pa & ion vertebra & 5025 & 91 & 185 & 86 & 0.015 \\
\hline Fusion/arthrodesis & & 2656 & 48 & 114 & 53 & 0.16 \\
\hline Osteotomy & & 129 & 2.3 & 14 & 6.5 & $<0.001$ \\
\hline Instrumentation & & 2977 & 54 & 126 & 58 & 0.18 \\
\hline Trauma & & 261 & 4.7 & 10 & 4.6 & 0.96 \\
\hline Oncology & & 302 & 5.4 & 28 & 13 & $<0.001$ \\
\hline Oncology—benign & & 89 & 1.6 & 4 & 1.9 & 0.78 \\
\hline Other & & 2558 & 46 & 115 & 53 & 0.040 \\
\hline
\end{tabular}

$\mathrm{CDC}=$ Centers for Disease Control and Prevention. 
Table 3. Bivariate analyses: Irrigation and débridement $(n=5761)$

\begin{tabular}{|c|c|c|c|c|c|c|}
\hline \multirow[t]{2}{*}{ Parameter } & \multicolumn{2}{|c|}{ No $(\mathrm{n}=5572[97 \%])$} & & \multicolumn{3}{|c|}{ Yes $(n=189[3.3 \%])$} \\
\hline & Mean (SD) & Range & & Mean (SD) & Range & $\mathrm{p}$ value \\
\hline Age (years) & $55(16)$ & $18-97$ & & $57(17)$ & $20-96$ & 0.12 \\
\hline Charlson index & $1.8(2.5)$ & $0-15$ & & $2.9(3.1)$ & $0-11$ & $<0.001$ \\
\hline \multirow[t]{2}{*}{ Duration (hours), $\mathrm{n}=5214$} & $3.5(2.1)$ & $0.22-18$ & & $4.5(2.7)$ & $0.75-15$ & $<0.001$ \\
\hline & & Number & Percent & Number & Percent & \\
\hline \multicolumn{7}{|l|}{ Sex } \\
\hline Male & & 2937 & 53 & 104 & 55 & 0.53 \\
\hline Female & & 2635 & 47 & 85 & 45 & \\
\hline \multicolumn{7}{|l|}{ Smoking } \\
\hline Yes & & 447 & 8.0 & 26 & 14 & 0.005 \\
\hline No & & 5125 & 92 & 163 & 86 & \\
\hline \multicolumn{7}{|l|}{ Malnutrition } \\
\hline Yes & & 345 & 6.2 & 22 & 12 & 0.003 \\
\hline No & & 5227 & 94 & 167 & 88 & \\
\hline \multicolumn{7}{|l|}{ Obesity } \\
\hline Yes & & 91 & 1.6 & 9 & 4.8 & 0.005 \\
\hline No & & 5481 & 98 & 180 & 95 & \\
\hline \multicolumn{7}{|l|}{ Steroid use } \\
\hline Yes & & 20 & 0.36 & 3 & 1.6 & 0.038 \\
\hline No & & 5552 & 100 & 186 & 98 & \\
\hline \multicolumn{7}{|l|}{ Morselized graft use } \\
\hline Yes & & 1874 & 34 & 82 & 43 & 0.005 \\
\hline No & & 3698 & 66 & 107 & 57 & \\
\hline \multicolumn{7}{|l|}{ Structural graft use } \\
\hline Yes & & 861 & 15 & 20 & 11 & 0.067 \\
\hline No & & 4711 & 85 & 169 & 89 & \\
\hline \multicolumn{7}{|l|}{ Vancomycin prophylaxis } \\
\hline Yes & & 84 & 1.5 & 0 & 0 & 0.12 \\
\hline No & & 5488 & 98 & 189 & 100 & \\
\hline \multicolumn{7}{|l|}{ Type of procedure } \\
\hline Anterior & & 1385 & 25 & 28 & 15 & 0.002 \\
\hline Posterior & & 2082 & 37 & 105 & 56 & $<0.001$ \\
\hline Cervical & & 1496 & 27 & 35 & 19 & 0.011 \\
\hline Thoracic & & 609 & 11 & 34 & 18 & 0.002 \\
\hline Lumbar & & 3800 & 68 & 133 & 70 & 0.53 \\
\hline Sacral & & 54 & 1.0 & 6 & 3.2 & 0.003 \\
\hline Single level & & 4573 & 82 & 165 & 87 & 0.064 \\
\hline Laminectomy/discectomy/p & ion vertebra & 5050 & 91 & 160 & 85 & 0.006 \\
\hline Fusion/arthrodesis & & 2669 & 48 & 101 & 53 & 0.13 \\
\hline Osteotomy & & 130 & 2.3 & 13 & 6.9 & $<0.001$ \\
\hline Instrumentation & & 2990 & 54 & 113 & 60 & 0.10 \\
\hline Trauma & & 262 & 4.7 & 9 & 4.8 & 0.97 \\
\hline Oncology & & 308 & 5.5 & 22 & 12 & $<0.001$ \\
\hline Oncology—benign & & 90 & 1.6 & 3 & 1.6 & 0.98 \\
\hline Other & & 2570 & 46 & 103 & 54 & 0.023 \\
\hline
\end{tabular}


thoracic versus lumbar versus sacral procedure; instrumentation; single-level procedure, laminectomy/ formaminotomy/discectomy/partial excision, fusion/arthrodesis, osteotomy, structural graft used, morcelized graft used, trauma procedure, oncology procedure, oncologybenign procedure, and other procedures. On average multiple procedures codes were given per patient. Bone grafting was monitored using CPT coding. We also studied the use of vancomycin powder in the wound (which initiated in 2012). In addition to these technical factors, we investigated if there were any differences in infection rates among surgeons by the different definition of infection by categorizing all surgeons who performed at least 100 procedures in this 10 -year timeframe (ICD-9 coding [Appendix 2; all supplemental materials are available with the online version of $\operatorname{CORR}^{\circledR}$.], CDC criteria for deep infection [Appendix 3], and I\&D for infection [Appendix 4]). All surgeons who performed less than 100 surgeries were aggregated to one group.

\section{Statistical Analysis}

Normality of our continuous data was tested using the Shapiro-Wilk test. We decided to use nonparametric tests because all continuous data showed a nonparametric distribution. For continuous variables, we used the MannWhitney $U$ test in bivariate analysis and for categorical variables a chi square or Fisher's exact test when applicable was used.

Baseline characteristics of study patients were summarized with frequencies and percentages for categorical variables and as mean \pm SD for continuous variables.

Duration of surgery was missing for 547 surgeries. We used mean imputation to include this variable in the multivariable analysis model.

In bivariate analysis, factors associated with SSI by all three definitions included: higher CCI, duration of the procedure, smoking, malnutrition, obesity, current and long-term use of corticosteroids (ICD-9 code), morcelized graft use, structural graft use, specific type of procedures, and specific surgeons. Variables with $\mathrm{p}<0.05$ were entered in a backward, stepwise, logistic regression analysis to assess their ability to predict the variation in SSI.

\section{Results}

After controlling for likely confounding variables using the multivariable analysis the CCI, the duration of the operation, obesity, and an anterior approach were retained in models based on each of the three definitions of SSI (pseudo $\mathrm{R}^{2}$, respectively, ICD-9 [Table 4], CDC [Table 5], and I\&D [Table 6]; 0.061, 0.063, 0.064; p < 0.001). Each
Table 4. Multivariable analysis for predicting SSI: ICD-9 code for infection $(\mathrm{n}=5761)$

\begin{tabular}{|c|c|c|c|c|c|c|}
\hline Parameter & $\begin{array}{l}\text { Odds } \\
\text { ratio }\end{array}$ & SE & $\mathrm{p}$ value & $95 \%$ & $\mathrm{CI}$ & $\begin{array}{l}\text { Pseudo } \\
\mathrm{R}^{2}\end{array}$ \\
\hline Duration (hours) & 1.1 & 0.028 & $<0.001$ & 1.0 & 1.2 & 0.061 \\
\hline Charlson index & 1.1 & 0.021 & $<0.001$ & 1.1 & 1.2 & \\
\hline Surgeon 7 & 0.43 & 0.17 & 0.030 & 0.20 & 0.92 & \\
\hline Malnutrition & 1.7 & 0.32 & 0.007 & 1.1 & 2.4 & \\
\hline Obesity & 3.4 & 0.93 & $<0.001$ & 2.0 & 5.8 & \\
\hline Surgeon 16 & 2.2 & 0.54 & 0.001 & 1.4 & 3.6 & \\
\hline $\begin{array}{l}\text { Type of procedure: } \\
\text { anterior }\end{array}$ & 0.55 & 0.082 & $<0.001$ & 0.41 & 0.73 & \\
\hline $\begin{array}{l}\text { Type of procedure: } \\
\text { other }\end{array}$ & 2.0 & 0.56 & 0.010 & 1.2 & 3.5 & \\
\hline $\begin{array}{l}\text { Others operated } \\
1-100 \times\end{array}$ & 1.3 & 0.15 & 0.026 & 1.0 & 1.6 & \\
\hline Surgeon 2 & 0.62 & 0.14 & 0.034 & 0.40 & 1.0 & \\
\hline
\end{tabular}

SSI = surgical site infection; ICD-9 = International Classification of Diseases, 9th Revision; $\mathrm{CI}=$ confidence interval.

Table 5. Multivariable analysis for predicting SSI: CDC criteria for deep infection $(\mathrm{n}=5761)$

\begin{tabular}{lllllll}
\hline Parameter & $\begin{array}{l}\text { Odds } \\
\text { ratio }\end{array}$ & SE & p value & $95 \%$ & CI & $\begin{array}{l}\text { Pseudo } \\
\mathrm{R}^{2}\end{array}$ \\
\hline Duration (hours) & 1.1 & 0.036 & $<0.001$ & 1.1 & 1.2 & 0.063 \\
Charlson index & 1.1 & 0.027 & 0.004 & 1.0 & 1.1 & \\
$\begin{array}{l}\text { Smoking } \\
\text { Type of procedure: }\end{array}$ & 2.0 & 0.41 & 0.001 & 1.3 & 3.0 & \\
$\quad$ other & & 0.85 & 0.003 & 1.4 & 4.9 & \\
$\begin{array}{l}\text { Obesity } \\
\text { Surgeon 16 }\end{array}$ & 2.9 & 1.0 & 0.002 & 1.5 & 5.7 & \\
$\begin{array}{l}\text { Surgeon 4 } \\
\text { Type of procedure: }\end{array}$ & 0.42 & 0.086 & $<0.001$ & 0.29 & 0.63 & \\
$\quad$ anterior & 1.8 & 0.40 & 0.004 & 1.2 & 2.8 & \\
$\quad \begin{array}{l}\text { Others operated } \\
\quad 1-100 \times\end{array}$ & 1.5 & 0.22 & 0.004 & 1.1 & 2.0 & \\
$\quad$ & & & & & & \\
\hline
\end{tabular}

SSI $=$ surgical site infection $; \mathrm{CDC}=$ Centers for Disease Control and Prevention; $\mathrm{CI}=$ confidence interval.

of these three models accounted for approximately $6 \%$ of the variability of developing an infection. The inclusion of malnutrition, smoking, specific procedures, and specific surgeons in the multivariable models varied by definition of infection.

\section{Discussion}

SSI delays recovery and can increase impairment after spine surgery [1]. Knowledge of risk factors for infection can inform preventive measures. Large databases have the 
Table 6. Multivariable analysis for predicting SSI: irrigation and débridement $(\mathrm{n}=5761)$

\begin{tabular}{|c|c|c|c|c|c|c|}
\hline Parameter & $\begin{array}{l}\text { Odds } \\
\text { ratio }\end{array}$ & SE & $\mathrm{p}$ value & $95 \%$ & CI & $\begin{array}{l}\text { Pseudo } \\
\mathrm{R}^{2}\end{array}$ \\
\hline Duration (hours) & 1.1 & 0.037 & $<0.001$ & 1.1 & 1.2 & 0.064 \\
\hline Charlson index & 1.1 & 0.028 & 0.001 & 1.0 & 1.1 & \\
\hline $\begin{array}{l}\text { Type of procedure: } \\
\text { osteotomy }\end{array}$ & 2.8 & 0.93 & 0.002 & 1.5 & 5.4 & \\
\hline Malnutrition & 2.0 & 0.49 & 0.003 & 1.3 & 3.3 & \\
\hline Obesity & 2.9 & 1.1 & 0.004 & 1.4 & 5.9 & \\
\hline $\begin{array}{l}\text { Others operated } \\
1-100 \times\end{array}$ & 1.4 & 0.21 & 0.033 & 1.0 & 1.9 & \\
\hline Surgeon 4 & 2.4 & 0.51 & $<0.001$ & 1.6 & 3.6 & \\
\hline $\begin{array}{l}\text { Type of procedure: } \\
\text { anterior }\end{array}$ & 0.41 & 0.090 & $<0.001$ & 0.27 & 0.63 & \\
\hline
\end{tabular}

SSI = surgical site infection; $\mathrm{CI}=$ confidence interval.

potential to generate more accurate and reliable assessments of risk factors for SSI, but they depend on definitions of infection based on easily searchable codes and other indexed data. We studied three different definitions of SSI based on coding data and the data easily abstracted from the medical record and found different numbers of infections but relatively consistent risk factors for infection.

This study should be interpreted with its limitations in mind. The data registry is representing a single center that might not be representative of the average center. We used ICD-9 and CPT codes to identify the initial diagnoses and procedures rather than review of the medical records. We imputed the mean for a considerable amount of data concerning the duration of surgery resulting from missing operation reports in our database. Furthermore, we only reviewed the medical records of patients who received the ICD-9 infection code (within 90 days of their initial surgery) and we might have missed infections diagnosed with CDC criteria and I\&D cases who did not receive the ICD-9 infection code. There is a possibility that some patients with SSI are treated outside of our system, but this is unlikely given that $87 \%$ of the cohort was followed for more than 90 days and $80 \%$ of the patients were followed for more than 180 days.

Our observed infection rates are within the range of reported infection rates $(<1 \%-11 \%)$ reported by Schuster et al. in their systematic review [13]. The rate of infection depends on the definition of infection. ICD-9 coding tended to include more infections than the other two criteria, because it included superficial infection and may also have included suspected but unconfirmed infections. The CDC criteria for deep infection and the return to the operating room for I\&D can be considered more stringent criteria. There is more subjectivity in the interpretation of skin changes and wound drainage than there is with the discovery of purulent drainage at surgery.
The duration of the operation, malnutrition, obesity, smoking, and the CCI as predictors of SSI were consistent with prior research $[6-9,15]$, but some were inconsistent in our study depending on the definition of infection used. The difference in risk factors arising from the different definitions of infection emphasizes both the clinical and scientific impact of the selected definition of infection. It is arguable that the same risk factors will surface if the cohort is of considerable size. On the other hand a small number of events (infections in our study) can have a substantial influence when the number of patients is small. The limitations of the selected definition of infection should be taken into account when designing a study and should be recognized when interpreting it.

As shown by Bohl et al. [2], by comparing two large nationwide orthopaedic databases for interdatabase reliability addressing hip fractures, there are large differences in comorbidities and adverse events reported between databases. We found that risk factors differ not only between databases, but also within databases depending on how a diagnosis or outcome is defined.

Observed differences in infection rate for several surgeons in bivariate analysis uncommonly persisted in multivariable analysis that accounted for confounding factors, suggesting that patient complexity is a more important factor in developing infections than individual surgeons. In our opinion, our analysis confirms the ability to identify whether certain surgeons are more or less prone to SSI than others, but we also realize that there may be variations in patient or surgery factors that are important and unaccounted for in our analysis. For instance, the surgeons with higher infection rates in our study were all orthopaedic oncologists. The fact that specific surgeon remained significant in the multivariable model indicates either that factors such as malignancy, chemotherapy, and radiation do not fully capture the risk associated with infection or that these surgeons have an infection risk over and above these other factors.

By comparing different definitions of infection in the same database we show that in reasonably large databases, there is similarity in the investigated risk factors independently of the definition of infection. This is an important finding when interpreting data extracted with a comparable methodology and might imply that ICD-9 codes based on large databases are suitable for investigating specific factors in spine surgery. Also the Centers for Medicare \& Medicaid Services uses ICD9 codes 996.67 (infection resulting from implant) and 998.59 (other postoperative infection) in combination with procedure codes for spinal fusion, arthrodesis of the shoulder/elbow, and repair of the shoulder/elbow in their Never Events program. An improved understanding of the risk factors of spine SSIs can inform preventive strategies and help with counseling of patients. We found that the study of SSI is influenced by the definition of infection, but the major risk factors are not altered 
as much as the frequency of infection. When studying SSIs, researchers might want to determine infections by different definitions for quality assurance purposes.

\section{References}

1. Bachoura A, Guitton TG, Smith RM, Vrahas MS, Zurakowski D, Ring D. Infirmity and injury complexity are risk factors for surgical-site infection after operative fracture care. Clin Orthop Relat Res. 2011;469:2621-2630.

2. Bohl DD, Basques BA, Golinvaux NS, Baumgaertner MR, Grauer JN. Nationwide Inpatient Sample and National Surgical Quality Improvement Program give different results in hip fracture studies. Clin Orthop Relat Res. 2014;472:1672-1680.

3. Capen DA, Calderone RR, Green A. Perioperative risk factors for wound infections after lower back fusions. Orthop Clin North Am. 1996;27:83-86.

4. Charlson ME, Pompei P, Ales KL, MacKenzie CR. A new method of classifying prognostic comorbidity in longitudinal studies: development and validation. J Chronic Dis. 1987;40:373-383.

5. Dubory A, Giorgi H, Walter A, Bouyer B, Vassal M, Zairi F, Dhenin A, Grelat M, Lonjon N, Dauzac C, Lonjon G. Surgicalsite infection in spinal injury: incidence and risk factors in a prospective cohort of 518 patients. Eur Spine J. 2014.

6. Durand F, Berthelot P, Cazorla C, Farizon F, Lucht F. Smoking is a risk factor of organ/space surgical site infection in orthopaedic surgery with implant materials. Int Orthop. 2013;37:723-727.

7. Jiang J, Teng Y, Fan Z, Khan S, Xia Y. Does Obesity Affect the Surgical Outcome and Complication Rates of Spinal Surgery? A Meta-analysis. Clin Orthop Relat Res. 2013.
8. Klein JD, Hey LA, Yu CS, Klein BB, Coufal FJ, Young EP, Marshall LF, Garfin SR. Perioperative nutrition and postoperative complications in patients undergoing spinal surgery. Spine (Phila Pa 1976). 1996;21:2676-2682.

9. Kurtz SM, Lau E, Ong KL, Carreon L, Watson H, Albert T, Glassman S. Infection risk for primary and revision instrumented lumbar spine fusion in the Medicare population. J Neurosurg Spine. 2012;17:342-347.

10. Massie JB, Heller JG, Abitbol JJ, McPherson D, Garfin SR. Postoperative posterior spinal wound infections. Clin Orthop Relat Res. 1992:99-108.

11. Olsen MA, Nepple JJ, Riew KD, Lenke LG, Bridwell KH, Mayfield J, Fraser VJ. Risk factors for surgical site infection following orthopaedic spinal operations. J Bone Joint Surg Am. 2008;90:62-69.

12. Schimmel JJ, Horsting PP, de Kleuver M, Wonders G, van Limbeek J. Risk factors for deep surgical site infections after spinal fusion. Eur Spine J. 2010;19:1711-1719.

13. Schuster JM, Rechtine G, Norvell DC, Dettori JR. The influence of perioperative risk factors and therapeutic interventions on infection rates after spine surgery: a systematic review. Spine (Phila Pa 1976). 2010;35:S125-137.

14. Simpson JM, Silveri CP, Balderston RA, Simeone FA, An HS. The results of operations on the lumbar spine in patients who have diabetes mellitus. J Bone Joint Surg Am. 1993;75:1823-1829.

15. Wimmer C, Gluch H, Franzreb M, Ogon M. Predisposing factors for infection in spine surgery: a survey of 850 spinal procedures. J Spinal Disord. 1998;11:124-128.

16. Xing D, Ma JX, Ma XL, Song DH, Wang J, Chen Y, Yang Y, Zhu SW, Ma BY, Feng R. A methodological, systematic review of evidence-based independent risk factors for surgical site infections after spinal surgery. Eur Spine J. 2013;22:605615. 